\title{
Etiology and clinical presentation of birth defects: population based study
}

\author{
Marcia L Feldkamp, ${ }^{1}$ John C Carey, ${ }^{1}$ Janice L B Byrne, ${ }^{1,2}$ Sergey Krikov, ${ }^{1}$ Lorenzo D Botto ${ }^{1}$
}

'Division of Medical Genetics, Department of Pediatrics, 295

Chipeta Way, Suite 2S010,

University of Utah School of

Medicine, Salt Lake City, UT, USA,

${ }^{2}$ Division of Maternal-Fetal

Medicine, Department of

Obstetrics and Gynecology,

University of Utah School of

Medicine, Salt Lake City, UT, USA

Correspondence to:

M L Feldkamp

marcia.feldkamp@hsc.utah.edu

Cite this as: $B M$ J 2017;357:j2249

http://dx.doi.org/10.1136/bmj.j2249

Accepted: 3 May 2017

\section{ABSTRACT}

OBJECTIVE

To assess causation and clinical presentation of major birth defects.

\section{DESIGN}

Population based case cohort.

SETTING

Cases of birth defects in children born 2005-09 to resident women, ascertained through Utah's population based surveillance system. All records underwent clinical re-review.

\section{PARTICIPANTS}

5504 cases among 270878 births (prevalence 2.03\%), excluding mild isolated conditions (such as muscular ventricular septal defects, distal hypospadias).

\section{MAIN OUTCOME MEASURES}

The primary outcomes were the proportion of birth defects with a known etiology (chromosomal, genetic, human teratogen, twinning) or unknown etiology, by morphology (isolated, multiple, minors only), and by pathogenesis (sequence, developmental field defect, or known pattern of birth defects).

\section{RESULTS}

Definite cause was assigned in $20.2 \%(n=1114)$ of cases: chromosomal or genetic conditions accounted for $94.4 \%$ ( $n=1052)$, teratogens for $4.1 \%$ ( $n=46$, mostly poorly controlled pregestational diabetes), and twinning for $1.4 \%$ ( $n=16$, conjoined or acardiac). The $79.8 \%(n=4390)$ remaining were classified as unknown etiology; of these $88.2 \%(n=3874)$ were isolated birth defects. Family history (similarly affected first degree relative) was documented in $4.8 \%(n=266)$. In this cohort, $92.1 \%$ (5067/5504) were live born infants (isolated and non-isolated birth defects): $75.3 \%$ (4147/5504) were classified as having an isolated birth defect (unknown or known etiology).

\section{WHAT IS ALREADY KNOWN ON THIS TOPIC}

Birth defects are common, costly, and critical

Two hospital based studies have tried to directly assess the proportion of birth defects with or without a known etiology

\section{WHAT THIS STUDY ADDS}

In this population based birth defect case cohort, the cause was established in only one in every five infants

The inability to understand etiology in four of five cases highlights the urgent need for better basic and translational research as a basis for primary prevention and care In addition, many birth defects are associated with fetal loss: estimates of the global burden of birth defects that consider only liveborn infants with isolated conditions will underestimate this burden by at least $25 \%$, and even more for selected conditions

\section{CONCLUSIONS}

These findings underscore the gaps in our knowledge regarding the causes of birth defects. For the causes that are known, such as smoking or diabetes, assigning causation in individual cases remains challenging. Nevertheless, the ongoing impact of these exposures on fetal development highlights the urgency and benefits of population based preventive interventions. For the causes that are still unknown, better strategies are needed. These can include greater integration of the key elements of etiology, morphology, and pathogenesis into epidemiologic studies; greater collaboration between researchers (such as developmental biologists), clinicians (such as medical geneticists), and epidemiologists; and better ways to objectively measure fetal exposures (beyond maternal self reports) and closer (prenatally) to the critical period of organogenesis.

\section{Introduction}

Birth defects are inborn errors of development. Broadly defined, they include any structural or functional anomaly with measureable effects on physical, intellectual, and social wellbeing. ${ }^{1}$ Birth defects represent a considerable and increasing clinical and public health challenge because of their worldwide impact on population health.

Major birth defects are common, costly, and critical. Collectively, they occur in one in 33 births, ${ }^{2}$ which in 2006 translated into an estimated 7.9 million babies worldwide. ${ }^{3}$ In the US alone, the cost of care during a single year (2004) was estimated at \$2.6bn ( $\mathrm{E} 2 \mathrm{bn}$, $€ 2.4 \mathrm{bn}) .{ }^{4}$ This estimate does not account for the considerable indirect and lifelong personal and societal costs. Finally, many birth defects critically affect survival. In the US, birth defects are the leading cause of infant mortality ${ }^{5}$ and in 2013 were associated with 4778 deaths, one in every five deaths in the first year of life.

The temporal trends are even more concerning. The occurrence of birth defects, with few localized exceptions (such as neural tube defects in countries that implemented folic acid fortification), has not decreased for many decades. Birth defects might indeed increase worldwide, with the alarming increase of known risk factors such as maternal diabetes and obesity. New threats such as the Zika epidemic are emerging. Unless progress is made in identifying and preventing the root causes of birth defects, these conditions will continue to have draining effects on the survival and health of individuals, families, and countries.

Progress in detecting and characterizing risk factors for birth defects has come mainly from epidemiologic studies. In fact, such studies have produced many associations between risk factors and groups of birth 
defects. Translating these associations to actual causes, however, has been difficult. As a first step in filling this gap, we evaluated the clinical and etiologic profile of birth defects in a well characterized population based case cohort through systematic review by clinicians, using a multidimensional assessment tool that incorporates etiology, morphology, and pathogenesis.

\section{Methods \\ Study population}

The data source for this study was Utah's statewide population based public health surveillance system (Utah Birth Defect Network, UBDN), housed at the Utah Department of Health. There is no patient involvement or contact as part of this surveillance system. The network monitors birth defects among all pregnancy outcomes (live births, stillbirths, pregnancy terminations) among Utah residents. If a termination occurred, existing medical records were ascertained and reviewed to determine eligibility. To identify potential cases, the program uses multiple reporting sources, both prenatal and postnatal. All reporting sources are mandated to regularly submit any potential diagnosis in infants aged up to 24 months and are legally protected to report if a diagnosis is made after 24 months. The detailed clinical information for each case is based on the abstracted prenatal and postnatal clinical records by trained data abstractors. The presence of a prenatal diagnosis without autopsy or postnatal confirmation is not sufficient for inclusion in the system, with few exceptions, the main one being anencephaly if well described by a perinatologist. For example, hydronephrosis based on only prenatal diagnosis was not eligible for inclusion unless it was confirmed postnatally. Some birth defects have not ever been eligible for inclusion in the surveillance system because it is more challenging to identify and ascertain all cases or they are not considered a birth defect-for example, isolated muscular ventricular septal defects, patent foramen ovale, patent ductus arteriosus, talipes equinovarus, congenital hip dysplasia/ dislocation, congenital pulmonary airway malformation, and cryptorchidism. Cases of fetal alcohol syndrome were included only if a major birth defect was diagnosed. Further details of the system's case ascertainment and medical record abstraction have been published elsewhere. ${ }^{67}$

\section{Clinical case review}

A team of clinicians with training in medical genetics (LDB, JCC, JLBB) reviewed case records, including inpatient and outpatient records, laboratory reports (such as genomic microarray), diagnostic evaluations (such as ultrasound images and echocardiograms), operative notes, and autopsy reports. Once a case was deemed eligible, the clinician generated a list of the major and minor defects and the timing of first diagnosis (prenatal or postnatal). Each defect was coded with the World Health Organization international classification of diseases (version 9) with British Paediatric Association extensions (ICD-9 BPA). In addition, the clinician provided three additional classifications for each case: known etiology (yes, no); isolated versus multiple (unrelated) birth defect versus syndromic (that is, known etiology: genetic or environmental); and whether the case was familial (yes, no). A case was considered familial if a first degree relative (parent or sib) had a concordant phenotype.

\section{Multidimensional etiologic classification}

To systematically capture the clinical presentation and etiology in the study cohort we developed and implemented a multidimensional classification with three axes: etiology (known, unknown), morphology (isolated, multiple majors, minors only), and pathogenesis (sequence, developmental field, or pattern). Table 1 summarizes the system and definitions. Briefly:

- Known etiology was assigned based on specific and conservative criteria and could be either genetic, environmental (teratogenic), or due to twinning:

- Genetic-cases were classified as having a known genetic etiology if there was documentation of abnormal chromosomal number (trisomy) or structure (insertion, deletion) or a single gene condition (such as Noonan syndrome)

- Environmental-this required documentation of exposure to a recognized human teratogen ${ }^{8}$ (for example, medication, such as valproic acid, or pregestational diabetes with abnormal hemoglobin $A_{1 c}$ concentration during the periconceptional period or early pregnancy). Among mothers noted to have diabetes (pregestational or gestational), we reviewed their timing of diagnosis before or during pregnancy, medication use for control of blood sugar, and if listed, the hemoglobin $\mathrm{A}_{1 \mathrm{c}}$ testing date and concentration. Women listed as having gestational diabetes with a diagnosis in the first trimester were reclassified as having pregestational diabetes if their hemoglobin $\mathrm{A}_{1 \mathrm{c}}$ was $>5.6$. To assign diabetes as a cause, the mother had to have evidence of poorly controlled pregestational diabetes and an infant with selected birth defects that, based on the published literature, were indicative of diabetic embryopathy ${ }^{9-11}$ : heterotaxy, holoprosencephaly, multiple vertebral defects, bilateral renal defects, or caudal dysgenesis. Conversely, pregestational diabetes in cases of isolated defects such as anencephaly or a congenital heart defect, or a major with minor defect was not considered as a known cause for those particular infants

- Twinning-abnormalities in twinning included either acardiac or conjoined twins.

- Morphology: a case with a single major birth defect (with or without a minor birth defect) was considered isolated. This definition includes isolated sequences. Infants without a major birth defect were included if they had a chromosomal anomaly (such as trisomy 21 with no reported major birth defect, normal echocardiogram, and none of the selected list of objective minor defects) or eligible genetic condition (such as skeletal dysplasia). Only a selected list of minor defects was classified and analyzed; these were 


\begin{tabular}{|c|c|}
\hline Group & Definition \\
\hline \multicolumn{2}{|l|}{ Etiology } \\
\hline Known & $\begin{array}{l}\text { Anomaly of chromosome number (trisomy 21) or structure (del 22q); single gene condition (such as Noonan syndrome); anomaly of gene expression } \\
\text { (methylation-related Beckwith-Wiedemann syndrome); established human teratogen (such as pregestational diabetes, valproic acid); specific twinning } \\
\text { abnormality (such as acardiac or conjoined twin) }\end{array}$ \\
\hline Unknown & No identifiable cause could definitively be established and documented \\
\hline \multicolumn{2}{|l|}{ Morphology } \\
\hline Isolated & $\begin{array}{l}\text { Single major malformation, with or without a non-objective minor defect. Note: a sequence (see below for definition) if isolated is considered an isolated } \\
\text { defect, as in the case spina bifida with clubfoot and hydrocephalus }\end{array}$ \\
\hline Multiple & Two or more unrelated major malformations \\
\hline Minor $^{\star}$ & Select, distinctive, and objective structural defect that is not clinically or surgically significant \\
\hline None & $\begin{array}{l}\text { No major or distinctive minor defects were detected. Case might still be eligible in the presence of an eligible chromosomal anomaly (such as child with } \\
\text { trisomy } 21 \text {, without a major defect, or one of the selected minor defects in the list of objective minors). }\end{array}$ \\
\hline \multicolumn{2}{|r|}{ 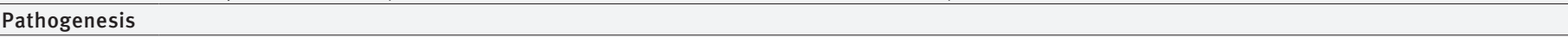 } \\
\hline Sequence $^{\dagger}$ & $\begin{array}{l}\text { Pattern of related malformations that occur as a result of a single primary malformation. Examples include spina bifida with hydrocephalus and clubfoot } \\
\text { (spina bifida sequence, with spina bifida as the primary malformation). A sequence can occur as an isolated defect (spina bifida sequence) or as multiple } \\
\text { defect (such as spina bifida sequence and cleft lip) }\end{array}$ \\
\hline $\begin{array}{l}\text { Developmental } \\
\text { field defect }{ }^{\ddagger}\end{array}$ & $\begin{array}{l}\text { Pattern of malformations resulting from the abnormal development of an embryonic unit (developmental field) that develops as a single unit in early } \\
\text { embryogenesis (such as during blastogenesis). Etiology of developmental field defects is typically heterogeneous. An example is the DiGeorge anomaly, } \\
\text { related to abnormal development and fate of populations of neural crest cells, leading to multiple structural anomalies and potentially caused by different } \\
\text { genetic abnormalities (such as deletion 22q11) or environmental factors (such as retinoic acid) }\end{array}$ \\
\hline Pattern $\S$ & $\begin{array}{l}\text { Non-random occurrence or pattern of multiple malformations without a known cause. Examples include the VATER/VACTERL recurrent and variable pattern } \\
\text { of anomalies. }\end{array}$ \\
\hline \multicolumn{2}{|r|}{$\begin{array}{l}\text { *Absent nails, auricular tag/pit, bifid uvula, branchial tag/pit, camptodactyly, cervical ribs, cup ear, cutis aplasia, cystic hygroma, ear lobe crease, ear lobe notch, extra nipples, iris coloboma, } \\
\text { lop ear (microtia type 1), natal tooth, neck webbing, overlapping finger, polydactyly type B: tag involves hand or foot (polydactyly is a major defect when involvement includes a full extra digit of } \\
\text { hand or foot), preauricular tag/pit, rocker bottom feet, single crease fifth finger, single transverse crease, single umbilical artery, syndactyly (toes), syndactyly (hands, mild, first flexion crease } \\
\text { involvement: syndactyly is a major defect when involvement is up to/include second flexion crease (moderate) and severe when it includes distal phalanx). } \\
\text { †Amniotic band, amniotic band with limb-body wall, arthrogryposis, frontonasal malformation, gastroschisis with congenital intestinal atresia, limb-body wall complex, Pierre Robin sequence, } \\
\text { Poland anomaly, urethral obstruction (that is, posterior urethral valves, urethral atresia/stenosis), urethral obstruction and renal agenesis (MCDK), renal (agenesis, multicystic dysplastic kidney, } \\
\text { infantile autosomal recessive polycystic kidney disease), spina bifida (hydrocephalus, club foot), Sturge-Weber syndrome. } \\
\text { łPentalogy of Cantrell, cloacal exstrophy, DiGeorge anomaly, holoprosencephaly, laterality, septo-optic dysplasia, sirenomelia, urorectal septum malformation. } \\
\text { §Caudal dysgenesis, VACTERL: vertebral anomalies, anal atresia, cardiovascular, tracheoesophageal fistula, esophageal atresia, renal and/or radial, limb, MURCS: Müllerian duct aplasia, renal } \\
\text { aplasia, and, cervicothoracic somite dysplasia, Goldenhar/OAV (oculo-auricular-vertebral). }\end{array}$} \\
\hline
\end{tabular}

selected because they can be considered as objective findings with limited variation in reporting and classification (table 1). This list included mainly discontinuous traits such as preauricular tags or single umbilical artery, rather than continuous traits such as hypertelorism, which require careful measurements and chart based decision criteria

- Pathogenesis: three groups were created and defined by mechanism based on embryology, not ICD-9 BPA codes (sequence, developmental field defect, or known pattern of birth defects, table 1). An example of a "known pattern" is the VATER/VACTERL association. This association was operationally defined as the presence of three or more VACTERL defects (vertebral defects, anal atresia, cardiac anomaly, esophageal atresia or tracheoesophageal (TE) fistula, renal malformation, radial limb malformation) with at least one being either esophageal atresia/TE fistula or anal atresia. ${ }^{12}$ To further promote consistency, the same clinical geneticist (JCC) reviewed and classified all cases of potential VACTERL association

Implementation of multidimensional classification For this study, the clinicians together developed a systematic process for the re-review of all cases. In general, each case was reviewed by one clinician, and the accuracy of the classification was further enhanced by assigning certain phenotypes to the clinician with the greatest expertise in that specialty. We re-reviewed the complete population based resident cohort for five consecutive birth years (1 January 2005 to 31 December
2009). We elected to assess this five year birth cohort because some genetic tests can be ordered well after infancy, changing the classification status. Case classification can also change as knowledge progresses. For example, cases of CHARGE association (coloboma, heart defect, choanal atresia, growth/developmental retardation, genital and ear abnormalities) were changed from "multiple congenital anomaly" to "syndrome/genetic" after mutations in the CHD7 gene were established as a cause in $2004^{13}$-in this situation, cases that met the established clinical criteria for CHARGE (with or without CHD7 mutation testing) were reclassified as "genetic." The classification was supported by an Access database module that captured both the classifications and comments from the clinical reviewers.

The cohort included 6547 confirmed cases. We excluded 834 cases of isolated birth defect: twin related $(\mathrm{n}=2)$; pelviectasis or hydronephrosis without evidence of obstruction ( $\mathrm{n}=47)$; small $(<4 \mathrm{~mm})$ secundum atrial septal defects $(\mathrm{n}=200)$; and distal (first degree) or megameatus type hypospadias $(\mathrm{n}=585)$. We also excluded spontaneous abortions occurring at $<20$ weeks' gestation ( $n=209)$. After exclusions, the final study cohort included 5504 cases.

Statistical analyses were done with SAS Enterprise Guide version 6.1 software (SAS Institute, Cary, NC, 2013).

\section{Patient involvement}

No patients were involved in setting the research question or the outcome measures, nor were they involved in 


\begin{tabular}{|c|c|c|c|}
\hline \multirow[b]{2}{*}{ Morphology } & \multicolumn{2}{|c|}{ Pregnancy outcome } & \multirow[b]{2}{*}{ Total } \\
\hline & Live birth & Fetal loss & \\
\hline \multicolumn{4}{|l|}{ Isolated } \\
\hline No of infants & 4147 & 204 & 4351 \\
\hline$\%$ total & $75.3 \%$ & $3.7 \%$ & $79 \%$ \\
\hline Prevalence/1000 & 15.3 & 0.8 & 16.1 \\
\hline \multicolumn{4}{|l|}{ Non-isolated } \\
\hline No of infants & 920 & 233 & 1153 \\
\hline$\%$ total & $16.7 \%$ & $4.2 \%$ & $21 \%$ \\
\hline Prevalence/1000 & 3.4 & 0.9 & 4.3 \\
\hline \multicolumn{4}{|l|}{ Total } \\
\hline No of infants & 5067 & 437 & 5504 \\
\hline$\%$ total & $92 \%$ & $7.9 \%$ & $100 \%$ \\
\hline Prevalence/1000 & 18.7 & 1.6 & 20.3 \\
\hline
\end{tabular}

the design and implementation of the study. There are no plans to involve patients in the dissemination of results.

\section{Results}

The population based study cohort included 5504 infants with major birth defects among 270878 total births (live births and stillbirths), giving a prevalence of $2.03 \%$. In this cohort, $92.1 \%$ (5067/5504) of cases (isolated and non-isolated) occurred in liveborn infants: 75.3\% (4147/5504) had an isolated defect (unknown and known etiology combined) (table 2). A positive family history (having a similarly affected first degree relative) was documented in $4.8 \%$ cases overall (266/5504). Compared with the underlying birth cohort (births in Utah, 2005-09), the affected cohort included more boys (57.7\%, P<0.001), even after we excluded cases known to be sex limited anomalies (such as hypospadias, 47,XXY/XYY/XXX, 45,X).

\section{Unknown etiology}

Overall, $79.8 \%$ of cases $(n=4390)$ were classified as unknown etiology (table 3), 3.6\% were known to be familial (isolated 3.7\%; multiple 2.7\%). Boys were over-represented in both isolated $(59.5 \%, \mathrm{P}<0.001)$ and multiple (55.4\%, $\mathrm{P}=0.02)$ case groups.

Among the unknown etiology case group, 344 (7.8\% of 4390) were further classified as a sequence $(n=242$, $70.3 \%)$, a developmental field defect ( $n=71,20.6 \%)$, or a known pattern ( $\mathrm{n}=31,9.0 \%)$ (table 4). Isolated defects accounted for most cases classified as a sequence $(\mathrm{n}=187,77.3 \%)$ or developmental field defect $(\mathrm{n}=50$, $70.4 \%$ ), whereas cases classified as a pattern were more likely to have multiple birth defects $(n=30,96.8 \%)$. Eighteen of 20 infants with birth defects consistent with VATER/VACTERL association (known pattern) were classified as unknown etiology.

\section{Known etiology}

A fifth $(20.2 \%, n=1114)$ of cases were assigned a known etiology (table 3 ). As shown in figure $1,90.4 \%$ of the cases with a known etiology were represented by the three common trisomies $(21,18,13)$, Turner syndrome, structural chromosomal abnormalities, and single gene disorders.

For the known etiology case group, 57 (5.1\% of 1114) were further classified as a sequence $(n=35,61.4 \%)$, a developmental field defect $(n=13,22.8 \%)$, or a known pattern ( $n=10,17.5 \%$ ) (data not shown). Of the remaining two cases with VATER/VACTERL association (known pattern), one case occurred with pregestational diabetes (teratogen) and another with partial trisomy (7q11.21 duplication) (chromosomal-structure).

\section{Discussion}

In this five year population based birth defect case cohort, systematic clinical review identified known etiology in only one in five-specific etiology could not be conclusively assigned in most (79.8\%) cases. We considered the etiology known if there was conclusive evidence of one of four factors: chromosomal abnormalities (structure or number), genetic conditions, twinning, or an established human teratogen. Methods to determine if an environmental exposure is a human teratogen were recently reviewed and applied to the birth defects associated with the Zika virus. ${ }^{14}$

Based on current science, our study revises and updates the historical findings from two well known hospital based studies of infants with birth defects. ${ }^{15} 16$ The overall conclusion remains that a specific cause cannot yet be determined for most birth defects, underscoring the current gaps in knowledge and the challenge of primary prevention.

\section{Comparison with other studies}

We focused on major birth defects (excluding some common defects), for a prevalence of $2 \%$. If we extrapolate from this conservative estimate, we estimate that each year a minimum of 78000 infants are born in the US with a serious birth defect. In 63000 , there would be no identifiable etiology. These figures are intended as minimum estimates. With different criteria for inclusion, investigators have reported a prevalence of $2.24 \%$ among infants with a birth defect diagnosed before discharge from the maternity ward or before the age of 5 days at Boston Hospital for Women ${ }^{16}$ and $5.5 \%{ }^{17}$ from the Texas Birth Defects Monitoring Program.

Our estimate of a known etiology in just over $20 \%$ is conservative. As genetic technology advances and more discoveries made on the genetic causes of birth defects, the proportion with a known cause will increase. For example, estimates of the genetic contribution to congenital heart disease (the most common birth defect) has increased, based on recent data suggesting that copy number variants and de novo mutations together could account for $15 \%$ of all cases. ${ }^{18-20}$ Also, for some well known risk factors, attribution of an exposure to a birth defect in an individual case remains challenging. The epidemiologic metric of attributable fraction (that is, the proportion of birth defects attributable to the exposure when cause is known) is applicable to populations, not individual cases. In this study, it was not 
Table 3 | Etiologic classification of birth defects stratified by morphology and pregnancy outcome in Utah, 2005-09. Figures are numbers (percentage) Morphology

\begin{tabular}{|c|c|c|c|c|c|c|c|c|}
\hline None & & Isolated & & $\geq 2$ majors & & Minors only ${ }^{*}$ & & \\
\hline $\begin{array}{l}\text { Live birth } \\
(\mathrm{n}=66,1.2 \%)\end{array}$ & $\begin{array}{l}\text { Fetal loss }^{\dagger} \\
(n=43,0.8 \%)\end{array}$ & $\begin{array}{l}\text { Live birth } \\
(n=4147,75.3 \%)\end{array}$ & $\begin{array}{l}\text { Fetal loss }^{\dagger} \\
(n=204,3.7 \%)\end{array}$ & $\begin{array}{l}\text { Live birth } \\
(\mathrm{n}=749,13.6 \%)\end{array}$ & $\begin{array}{l}\text { Fetal loss }^{\dagger} \\
(n=137,2.9 \%)\end{array}$ & $\begin{array}{l}\text { Live birth } \\
(\mathrm{n}=105,1.9 \%)\end{array}$ & $\begin{array}{l}\text { Fetal loss }^{\dagger} \\
(n=53,1.0 \%)\end{array}$ & $\begin{array}{l}\text { Total } \\
(n=5504)\end{array}$ \\
\hline
\end{tabular}

Known etiology

\begin{tabular}{|c|c|c|c|c|c|c|c|c|c|}
\hline No (\%) total & $66(5.9)$ & $43(3.9)$ & $407(36.5)$ & $70(6.3)$ & $287(25.8)$ & $83(7.5)$ & $105(9.4)$ & $53(4.8)$ & $1114(20.2)$ \\
\hline Chromosomal abnormality & 58 & 43 & 285 & 52 & 183 & 67 & 103 & 53 & 844 \\
\hline Number & 41 & 41 & 216 & 47 & 103 & 63 & 92 & 53 & 656 \\
\hline Structure & 17 & 2 & 69 & 5 & 80 & 4 & 11 & - & 188 \\
\hline Genetic & 8 & - & 106 & 5 & 80 & 7 & 2 & - & 208 \\
\hline Expression & - & - & 3 & - & 4 & - & - & - & 7 \\
\hline Single gene & 8 & - & 103 & 5 & 76 & 7 & 2 & - & 201 \\
\hline Teratogen & - & - & 15 & 1 & 23 & 7 & - & - & 46 \\
\hline Diabetes & - & - & 8 & - & 18 & 7 & - & - & 33 \\
\hline Infections & - & - & 5 & 1 & 3 & - & - & - & 9 \\
\hline Medications & - & - & 2 & - & 2 & - & - & - & 4 \\
\hline Twinning & - & - & 1 & 12 & 1 & 2 & - & - & 16 \\
\hline Acardiac & - & - & - & 8 & - & - & - & - & 8 \\
\hline Conjoined & - & - & 1 & 4 & 1 & 2 & - & - & 8 \\
\hline \multicolumn{10}{|l|}{ Unknown etiology } \\
\hline No (\%) total & - & - & $3740(85.2)$ & $134(3.1)$ & $462(10.5)$ & $54(1.2)$ & - & - & $4390(79.8)$ \\
\hline
\end{tabular}

*Minors only ( $n=158$ ) - chromosomal ( $n=156)$ : trisomy 21 97, Turner 29, trisomy 18 10, 45,X mosaic 3, Klinefelter 3, trisomy 21 mosaic 2, microdeletion 5, partial trisomy 3, del/dup 1, del 5p 1, del 22q 1, DiGeorge 1; genetic $(n=2):$ Ol type 11, fragile X1.

tIncludes stillbirths ( $\geq 20$ weeks' gestation) and pregnancy terminations (any gestation)

Table 4 | Pathogenesis of 344 cases of birth defects with unknown etiology, stratified by morphology and pregnancy outcome in Utah, 2005-09. Figures are numbers (percentage)

\begin{tabular}{|c|c|c|c|c|c|}
\hline & \multicolumn{4}{|c|}{ Morphology } & \multirow[b]{3}{*}{ Total } \\
\hline & \multicolumn{2}{|c|}{ Isolated } & \multicolumn{2}{|l|}{$\geq 2$ majors } & \\
\hline & Live birth & Fetal loss ${ }^{*}$ & Live birth & Fetal loss ${ }^{*}$ & \\
\hline \multicolumn{6}{|l|}{ Sequence $(n=242,70.3 \%)$} \\
\hline Spina bifida, hydrocephalus, clubbed foot & 46 & 5 & 14 & - & $65(26.9)$ \\
\hline Renal $^{\dagger}$ & 13 & 16 & 4 & 1 & $34(14.0)$ \\
\hline Arthrogryposis & 15 & 2 & 10 & 4 & $31(12.8)$ \\
\hline Pierre Robin & 21 & - & 8 & - & $29(12.0)$ \\
\hline Amniotic band & 11 & 8 & 1 & - & $20(8.3)$ \\
\hline Urethral obstruction ${ }^{\ddagger}$ & 10 & 4 & 1 & 2 & $17(7.0)$ \\
\hline Limb-body wall with/without amniotic band & 2 & 11 & - & 2 & $15(6.2)$ \\
\hline Gastroschisis with atresia ${ }^{\S}$ & 11 & 1 & 1 & - & $13(5.4)$ \\
\hline Urethral obstruction with renal" & 4 & 2 & 5 & - & $11(4.5)$ \\
\hline Poland anomaly & 2 & - & 1 & - & $3(1.2)$ \\
\hline Sturge-Weber & 3 & - & - & - & $3(1.2)$ \\
\hline Frontonasal malformation & - & - & 1 & - & $1(0.4)$ \\
\hline Total & $138(57.0)$ & $49(20.2)$ & $46(19.0)$ & $9(3.7)$ & 242 \\
\hline \multicolumn{6}{|l|}{ Developmental field defect $(n=71,20.6 \%)$} \\
\hline Laterality & 27 & 1 & 8 & 1 & $37(52.1)$ \\
\hline Holoprosencepahly & 10 & 2 & 5 & 4 & $21(29.6)$ \\
\hline Septo-optic dysplasia & 2 & - & 2 & - & $4(5.6)$ \\
\hline Urorectal septum defect & 3 & - & 1 & - & $4(5.6)$ \\
\hline Pentalogy of Cantrell & 2 & - & - & - & $2(2.8)$ \\
\hline Sirenomelia & 2 & - & - & - & $2(2.8)$ \\
\hline Cloacal exstrophy & 1 & - & - & - & $1(1.4)$ \\
\hline Total & $47(66.2)$ & $3(4.2)$ & $16(22.5)$ & $5(7.0)$ & 71 \\
\hline \multicolumn{6}{|l|}{ Pattern $(n=31,9.0 \%)$} \\
\hline VATER/VACTERL & - & - & 16 & 2 & $18(58.1)$ \\
\hline Goldenhar/OAV & 1 & - & 8 & 1 & $10(32.3)$ \\
\hline Caudal dysgenesis & - & - & 3 & - & $3(9.8)$ \\
\hline Total & $1(3.2)$ & 0 & $27(87.1)$ & $3(9.6)$ & 31 \\
\hline
\end{tabular}

Goldenhar/OAV (oculo-auricular-vertebral); VACTERL: vertebral anomalies, anal atresia, cardiovascular, tracheoesophageal fistula, esophageal atresia, renal and/or radial, limb.

*Includes both stillbirths and pregnancy terminations.

tRenal agenesis, multicystic dysplastic kidneys infantile autosomal recessive polycystic kidney disease.

¥Posterior urethral valves, urethral atresia/stenosis.

$\S$ Congenital intestinal atresia (does not include acquired atresia after delivery).

ףUrethral obstruction with renal agenesis, multicystic dysplastic kidneys infantile autosomal recessive polycystic kidney disease 


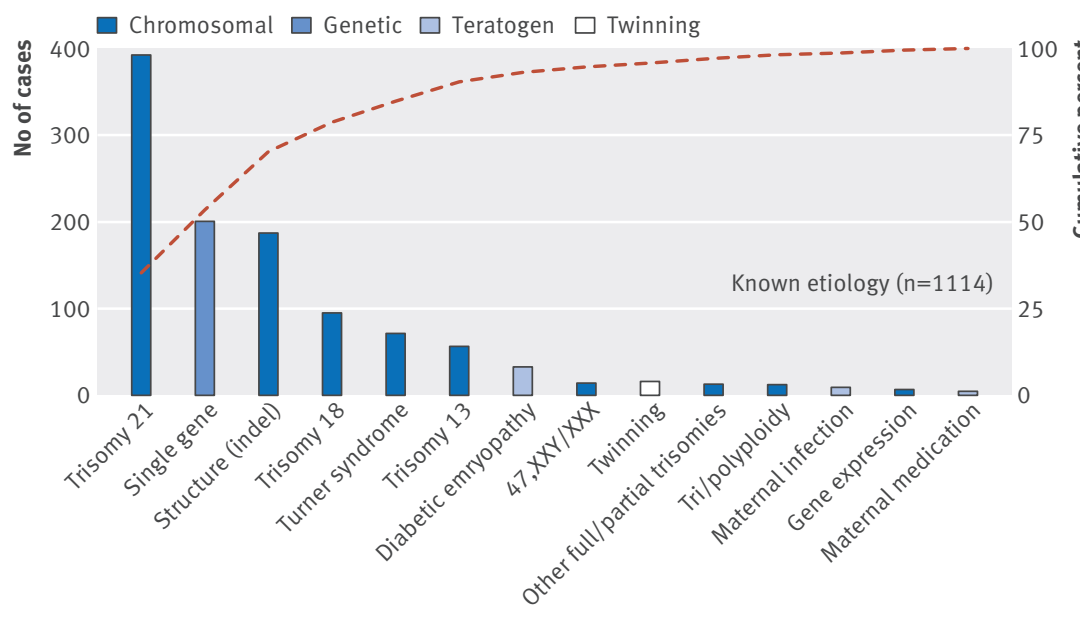

Fig 1 Number and cumulative percent of cases of birth defects with a known etiology, Utah 2005-09 interactions between the genetic profiles of parents and embryo and the environmental milieu during preconception and early gestation. For some birth defects, some progress has been made over the past decades, such as the contribution of microdeletions (such as deletion 22q11 in cases of heart defects and cleft palate ${ }^{22-25}$ ) and novel single gene mutations (such as CHD7 mutations in CHARGE syndrome ${ }^{13}$ ). While these genetic causes are relatively straightforward, however, it is likely that further research will discover more complex networks accounting for genetic and environmental contributions to birth defects etiology. Accumulating evidence is uncovering developmental networks that when disrupted can cause birth defect syndromes. ${ }^{26}$ Some of these networks could also be influenced by environmental exposures, such as the midline patterning network related to the sonic hedgehog gene, which directly involves cholesterol metabolism. For example, the risk for holoprosencephaly could be increased not only by mutations in sonic hedgehog but potentially also by environmental influences (yet undiscovered) that alter the embryonic cholesterol biosynthesis, perhaps interacting with sonic hedgehog variants. ${ }^{26}$

Birth defects know no geographic boundary and occur in every country of the world. Because many countries do not have the capacity to monitor birth defects that occur among all pregnancy outcomes, it is difficult to estimate their true worldwide prevalence and global burden. Based on the findings of this study, however, if we count only those infants live born with an isolated birth defect, $25 \%$ of the cases will be missed. The resulting underestimation of the burden of disease can have serious policy implications and hinder the investments in research and interventions to better prevent and treat these major threats to childhood survival and lifelong health.

Research to understand birth defect etiology requires a well defined and clinically characterized case group. Cases with known etiology must be carefully identified and excluded to maximize the chance of discovery. ${ }^{27}$ While commonly used birth defect classification schemes (such as ICD-9 or ICD-10) are valuable for general purposes such as studies on morbidity and mortality, they are not ideal in the evaluation of etiologies or trends ${ }^{28}$ and could overestimate prevalence. ${ }^{29-32}$ These coding systems are typically organized by anatomy or function rather than cause or embryologic process. Few studies have applied classifications specific to birth defects to population based cohorts. One of these, the National Birth Defects Prevention Study, has leveraged the collaboration of clinical geneticists and epidemiologists to pursue discovery of modifiable causes of birth defects. ${ }^{33-35}$ Continued progress will require the combined effort and a multidisciplinary approach that incorporates not only the clinical evaluation by dysmorphologists/clinical geneticists and the methodological expertise of epidemiologists but also includes experts in developmental biology, pharmacology, infectious diseases, immunology, and bioinformatics, in addition to a more objective assessment of periconceptional exposures that improve on the typical maternal self 
reports. Finally, it would be helpful to integrate etiology, morphology, and pathogenesis assessment into the basic framework of epidemiologic studies. Such integration will improve precision and assist researchers to focus research initiatives and investigate common pathways among birth defects.

\section{Limitations}

This study has potential limitations. The birth prevalence of $2.03 \%$ reported in this study is lower than the 2.24-5.5\% reported elsewhere. ${ }^{21617}$ Such lower prevalence estimates could relate to the eligibility criteria of the Utah surveillance system, which exclude some common mostly milder conditions that are variably defined and ascertained (such as muscular ventricular septal defects, clubfoot, cryptorchidism). Also, because cases were classified based on data abstracted from mother and infant medical records, there is a possibility that critical information for appropriate classification was unavailable at the time of medical record abstraction. In addition, we could have underestimated the proportion caused by a teratogen if an exposure (such as maternal pregestational diabetes) was not noted in the medical record or not queried by the physician of record. The information in these medical records comes from different specialists, often including perinatologists, genetic counselors, neonatologists, and/or pediatric geneticists. Whereas some level of etiologic under-ascertainment cannot be excluded, it is unlikely that an established environmental cause of birth defects would be missed by everyone involved in the care of the mother and the child. For a genetic investigation, the laboratory evaluation (such as karyotype, microarray) was determined by the clinician(s) caring for the infant and was tailored to the clinical presentation. We would expect some variation within the practice of medicine.

\section{Conclusion and public health implications}

Understanding the etiology of birth defects should be both a public health and research priority. Our findings underscore the large gaps in current knowledge of the causes of birth defects. These gaps in turn represent opportunities for both basic and translational researchers. Such research can be particularly powerful and efficient if done in collaboration with population based birth defect surveillance programs enhanced with clinical expertise and meaningful case classification. ${ }^{36}$ Advances in the knowledge of the causal pathway leading to birth defects can be the basis for better primary prevention interventions, resulting in longer and better lives. For clinicians and parents, it is important to understand what can be done today to prevent birth defects, in particular the role of preconception care focusing on optimal women's health (including screening/treating chronic illnesses, attaining folic acid sufficiency, etc). In addition, investigation of potential causes of a birth defect at the time of diagnosis (such as whether a genetic condition is present) can help to better plan management and appropriately counsel families, including the relief of anxiety related to unfounded information and guilt.
Contributors: MLF, JCC, JLBB, and LDB conceived and designed the project. SK and MLF cleaned and conducted the analysis for the project. All authors interpreted the data, drafted the manuscript, and assisted with manuscript revisions. MLF is guarantor.

Funding: This publication was supported by a cooperative agreement (No U01DD000490) from the Centers for Disease Control and Prevention. Its contents are solely the responsibility of the authors and do not necessarily represent the official views of the Centers for Disease Control and Prevention. Data were provided by the Utah Birth Defect Network, a program within the Utah Department of Health. This project is supported by the Health Resources and Services Administration (HRSA) of the US Department of Health and Human Services (HHS) under grant No B04MC25374. This information or content and conclusions are those of the author and should not be construed as the official position or policy of, nor should any endorsements be inferred by HRSA, the US Government, or the Utah Department of Health.

Competing interests: All authors have completed the ICMJE uniform disclosure form and declare no support from any organization for the submitted work, no financial relationships with any organizations that might have an interest in the submitted work in the previous three years, and no other relationships or activities that could appear to have influenced the submitted work.

Ethical approval: Not required.

Data sharing: No additional data available.

Transparency: The lead author (the manuscript's guarantor) affirms that this manuscript is an honest, accurate, and transparent account of the study being reported; that no important aspects of the study have been omitted; and that any discrepancies from the study as planned (and, if relevant, registered) have been explained.

This is an Open Access article distributed in accordance with the Creative Commons Attribution Non Commercial (CC BY-NC 4.0) license, which permits others to distribute, remix, adapt, build upon this work non-commercially, and license their derivative works on different terms, provided the original work is properly cited and the use is non-commercial. See: http://creativecommons.org/licenses/ by-nc/4.0/

1 World Health Organization (WHO). Sixty-third World Health Assembly. Birth Defects. Report by the Secretariat. A63/10. April 2010

2 Centers for Disease Control and Prevention (CDC). Update on overall prevalence of major birth defects--Atlanta, Georgia, 1978-2005. MMWR Morb Mortal Wkly Rep 2008;57:1-5.

3 Christianson A, Howson CP, Modell B. March of Dimes Global Report on Birth Defects. The Hidden Toll of Dying and Disabled Children. March of Dimes Birth Defects Foundation, 2006

4 Russo CA, Elixhauser A. Hospitalizations for Birth Defects, 2004. HCUP Statistical Brief \#24.U.S. Agency for Healthcare Research and Quality, 2007.

5 Mathews TJ, MacDorman MF, Thoma ME. Infant mortality statistics from the 2013 period linked birth/infant death data set. National vita statistics reports; National Center for Health Statistics; 2015;64(9).

6 Feldkamp M, Macleod L, Young L, Lecheminant K, Carey JC. The methodology of the Utah Birth Defect Network: congenital heart defects as an illustration. Birth Defects Res A Clin Mol Teratol 2005;73:693-9. doi:10.1002/bdra.20212.

7 Stevenson DA, Carey JC, Byrne JLB, Srisukhumbowornchai S, Feldkamp ML. Analysis of skeletal dysplasias in the Utah population. Am J Med Genet A 2012;158A:1046-54. doi:10.1002/ajmg.a.35327.

8 Stevenson RE. Human Malformations and related anomalies. In: Stevenson RE, Hall JG, Everman DB, Solomon BD, eds. Human Malformations and Related Anomalies.3rd ed. Oxford University Press, 2016:1-35.

9 Mills JL. Malformations in infants of diabetic mothers. Teratology 25:385-94. 1982. Birth Defects Res A Clin Mol Teratol 2010;88: 769-78.

10 Correa A, Gilboa SM, Besser LM, et al. Diabetes mellitus and birth defects. Am J Obstet Gynecol 2008;199:237.e1-9. doi:10.1016/j. ajog.2008.06.028.

11 Gilbert-Barness E. Teratogenic causes of malformations. Ann Clin Lab Sci 2010;40:99-114

12 Botto LD, Khoury MJ, Mastroiacovo P, et al. The spectrum of congenital anomalies of the VATER association: an international study. Am / Med Genet 1997:71:8-15. doi:10.1002/ (SICI)1096-8628(19970711)71:1<8::AID-AJMG2>3.0.CO;2-V

13 Vissers LE, van Ravenswaaij CM, Admiraal R, et al. Mutations in a new member of the chromodomain gene family cause CHARGE syndrome. Nat Genet 2004;36:955-7. doi:10.1038/ng1407.

14 Rasmussen SA, Jamieson DJ, Honein MA, Petersen LR. Zika virus and birth defects - reviewing the evidence for causality. N Engl / Med 2016:374:1981-7. doi:10.1056/NEIMsr1604338. 
15 Martínez-Frías ML, Bermejo E, Frías JL. Pathogenetic classification of a series of 27,145 consecutive infants with congenital defects. Am J Med Genet 2000:90:246-9. doi:10.1002/

(SICI)1096-8628(20000131)90:3<246::AID-AJMG12>3.0.CO;2-Q.

16 Nelson K, Holmes LB. Malformations due to presumed spontaneous mutations in newborn infants. N Engl / Med 1989;320:19-23. doi:10.1056/NEJM198901053200104.

17 Texas Department of State Health Services (TDSHS). Texas Birth Defects Registry's Report of Birth Defects among 1999-2011 Deliveries: Summary and Key Findings. 2015. http://www.dshs.state. tx.us/birthdefects/data/BD_Data_99-11/Report-of-Birth-DefectsAmong-1999-2011-Deliveries.aspx.

18 Yuan S, Zaidi S, Brueckner M. Congenital heart disease: emerging themes linking genetics and development. Curr Opin Genet Dev 2013;23:352-9. doi:10.1016/j.gde.2013.05.004.

19 Al Turki S, Manickaraj AK, Mercer CL, et al. UK10K Consortium. Rare variants in NR2F2 cause congenital heart defects in humans. Am J Hum Genet 2014;94:574-85. doi:10.1016/j.ajhg.2014.03.007.

20 Warburton D, Ronemus M, Kline J, et al. The contribution of de novo and rare inherited copy number changes to congenital heart disease in an unselected sample of children with conotruncal defects or hypoplastic left heart disease. Hum Genet 2014;133:11-27. doi:10.1007/s00439-013-1353-9.

21 Higurashi M, lijima K, Sugimoto Y, et al. The birth prevalence of malformation syndromes in Tokyo infants: a survey of 14,430 newborn infants. Am J Med Genet 1980;6:189-94. doi:10.1002/ ajmg.1320060303.

22 de la Chapelle A, Herva R, Koivisto M, Aula P. A deletion in chromosome 22 can cause DiGeorge syndrome. Hum Genet 1981;57:253-6. doi:10.1007/BF00278938.

23 Kelley RI, Zackai EH, Emanuel BS, Kistenmacher M, Greenberg F, Punnett HH. The association of the DiGeorge anomalad with partial monosomy of chromosome 22. J Pediatr 1982;101:197-200. doi:10.1016/S0022-3476(82)80116-9.

24 Amati F, Mari A, Digilio MC, et al. 22q11 deletions in isolated and syndromic patients with tetralogy of Fallot. Hum Genet 1995;95:47982. doi:10.1007/BF00223856.

25 Takahashi K, Kido S, Hoshino K, Ogawa K, Ohashi H, Fukushima Y. Frequency of a 22q11 deletion in patients with conotruncal cardiac malformations: a prospective study. Eur J Pediatr 1995;154:878-81. doi:10.1007/BF01957496.
26 Jorde LB, Carey JC, Bamshad MJ. Developmental genes. In: Jorde LB, Carey JC, Bamshad MJ, eds. Medical Genetics.4th ed. Mosby Elsevier, 2016: 193-211

27 Rasmussen SA, Olney RS, Holmes LB, Lin AE, Keppler-Noreuil KM, Moore CA. National Birth Defects Prevention Study. Guidelines for case classification for the National Birth Defects Prevention Study. Birth Defects Res A Clin Mol Teratol 2003;67:193-201. doi:10.1002/ bdra.10012.

28 Rasmussen SA, Moore CA. Effective coding in birth defects surveillance. Teratology 2001;64(Suppl 1):S3-7. doi:10.1002/tera.1077.

29 Källén B, Hay S, Klingberg M. Birth defects monitoring systems accomplishments and goals. In: Kalter H, ed. Issues and Reviews in Teratology.Plenum Publishing Corporation, 1984 1-22doi:10.1007/978-1-4615-7314-2_1.

30 Cunniff C, Kirby RS, Senner JW, et al. Deaths associated with rena agenesis: a population-based study of birth prevalence, case ascertainment, and etiologic heterogeneity. Teratology 1994;50:2004. doi:10.1002/tera.1420500305.

31 De Wals P, Trochet C, Pinsonneault L. Prevalence of neural tube defects in the province of Quebec, 1992. Can I Public Health 1999:90:237-9.

32 Reefhuis J, de Walle HE, Cornel MC. Artefactual increasing frequency of omphaloceles in the Northern Netherlands: lessons for systematic analysis of apparent epidemics. Int J Epidemiol 1999;28:258-62. doi:10.1093/ije/28.2.258.

33 Browne ML, Van Zutphen AR, Botto LD, Louik C, Richardson S, Druschel CM. Maternal butalbital use and selected defects in the national birth defects prevention study. Headache 2014:54:54-66. doi: $10.1111 /$ head.12203

34 Reefhuis J, Devine O, Friedman JM, Louik C, Honein MA. National Birth Defects Prevention Study. Specific SSRIs and birth defects: Bayesian analysis to interpret new data in the context of previous reports. BMJ 2015;351:h3190. doi:10.1136/bmj.h3190.

35 Botto LD, Krikov S, Carmichael SL, Munger RG, Shaw GM, Feldkamp ML. National Birth Defects Prevention Study. Lower rate of selected congenital heart defects with better maternal diet quality: a population-based study. Arch Dis Child Fetal Neonatal Ed 2016;101:F43-9. doi:10.1136/archdischild-2014-308013.

36 Moore CA, McCabe ERB. Editorial utility of population-based birth defects surveillance for monitoring the health of infants and as a foundation for etiologic research. Birth Defects Res A Clin Mol Teratol 2015;103:895-8. doi:10.1002/bdra.23421. 